\title{
On the Question of the Content of Educational Strategy Concept
}

\author{
Lyudmila Slavnetskova, Tatyana Odintsova, Kseniya Chepelenko, and Yulia Baurova* \\ Yuri Gagarin State Technical University of Saratov, Politechnicheskaya Str., 77, 410054 Saratov, \\ Russia
}

\begin{abstract}
The problem-thematic focus of the article is concentrated on the phenomenon of pedagogical strategies. Pedagogical strategies are one of the central concepts of pedagogical discourse, reflecting the specifics of the pedagogical reality of our time. Stressing the great scientific and practical interest of modern researchers to the phenomenon of pedagogical strategies, the article discusses the importance and argues the need to work out the concept of pedagogical strategy for the development of conceptual and terminological apparatus of pedagogy. The article emphasizes the importance of the strategic vector of higher education pedagogy, where its significance is especially great. The analytical description of the presented definitions of the pedagogical strategy concept, revealing its essential features, allows us to outline the connotative space of the term, which cannot yet be recognized as finally formed and completed.
\end{abstract}

\section{Introduction}

The relevance, high frequency of the lexeme «strategy» use, which serves in the modern lexicon in its scientific and applied meanings, today does not need detailed proofs. As for the issue of conceptualizing the notion of strategy, it undoubtedly belongs to one of the most significant questions facing the sociology of science.

It is generally accepted that the emerging current theory of strategy has a philosophical foundation. As a theoretical construct, strategy is the subject of close attention not only to philosophers, but also to researchers of various disciplines, including researches in the field of pedagogical sciences.

The main intention of this article is entirely in the mainstream of the indicated issues; it is aimed at considering the subject horizon of the concept «strategy», developed in the context of domestic pedagogical discourse. Structural operationalization of the key concept of the work is aimed at explicating the semantic depth and identifying the maximum full scope of the meanings inherent in it.

The semantic core of a word is indicated by its etymology. The historical roots of the lexeme «strategy», dating back to antiquity (from the Greek «stratos» - army, «ago» leading, strategos, chief of the army), are associated with the art of warfare. Starting "with the works of such early strategists (who did not even know that they were), such as the

\footnotetext{
* Corresponding author: workingday08@mail.ru
} 
Roman leader and author Frontinus and the Byzantine emperor Mauritius, the theory of strategy has sporadically developed over two thousand years» [1].

One of the detailed modern definitions of strategy belongs to Karl von Clausewitz, the author of the treatise «On War» (1834). The development of the term is associated with the expansion of the area of its use, the enrichment of its connotative field. So, starting from the 1960s., the term strategy appears in the English-language literature on management ( $\mathrm{P}$. Allen, J. Burke, E. N. Berkovich, R. Cooper, P. Lopence, J. Loughman, etc.). Somewhat later, from the works of research by foreign scientists (R. Ackoff, I. Ansof, P. Drucker, B. Karlof), the term strategy is transposed into the context of domestic science, where it is productively developed by I. Dakhov, P.S. Zavyalov, V.D. Markova, E.A. Utkin. At the end of the twentieth century, the term was actualized in psychology, philosophy and pedagogy. Nevertheless, it should be admitted that strategy as a science is in the process of its formation today.

\section{Materials and Methods}

The content of the «strategy» category is very diverse; this concept is now applicable to almost all spheres of human activity. The scientific status of the term was updated; moreover, in the scientific discourse of the 21 st century, strategizing is positioned as a new area of professional knowledge. Stable phrases such as business strategy, strategic management, educational strategy, information strategy, art strategy, creative strategy and some others are firmly entrenched in the current humanitarian thesaurus.

It should be noted that the complexity of the phenomenon under consideration correlates with the ambiguity and multiplicity of its interpretations. In academic sources, several stable formulations of the concept have become widespread, the semantic axis of which is the lexeme plan. So, in particular, one of the reference editions of recent years gives the following definition: a strategy is «a certain step-by-step action plan (set of rules) developed in conditions of uncertainty in order to achieve the desired result» [2], "A plan of carrying out or actions, a deliberately composed set of operations to solve a problem or achieve a goal» [3].

The semantic outline of the above formulations is seen in the concept of the essence of the strategy in the interpretation of A.V. Petrova: «a strategy is a long-term plan to achieve a long-term goal or a desired result through the step-by-step implementation of detailed actions» [4].

These definitions correspond to the definition in which the strategy is interpreted as «a strategic landmark, a given direction of development, which in the long term should lead to the achievement of the set goal» [5].

A wide semantic range of meanings unfolds the definition of the lexeme strategy, borrowed from management theory, where strategy is understood as a plan, and a clever technique, and a pattern (a principle of behavior, a scheme of actions) and a position (the ratio of «organization» with the «external environment», and perspective (concept) [6]. The dissertation research and a number of articles by the author of these lines are devoted to the problem of creative strategies [7-13], as well as a programmatic article by O.A. Krivtsun, who defined the content of the concept of creative strategies in the category of patterns «built, verified, thoughtful artistic behavior in the integral system of the creator's activity» [14]. 


\section{Results and Discussion}

An overview of the definitions presented allows us to draw a logical conclusion: a strategy can be understood as a complex, effective tool with which it is possible to successfully navigate the current situation, as well as achieve the intended development goals. Strategies «give an organized character to events controlled by a person» [15], representing a «longterm plan for the transition from the current state to the target» based on reliable and farreaching forecasts [16].

Thinking about the specifics of strategy in pedagogy, we mean pedagogical strategy. The scope of the concept of pedagogical strategy represents the variety of professional and behavioral activity forms, which, as is commonly believed, is most fully actualized in the field of higher education. The concept of pedagogical strategy as a long-term process, a logically constructed sequence of expedient actions can refer both to the activities of the teaching staff of a higher educational institution as a whole, and to the characteristics of the activities of an individual teacher.

In the pedagogical literature, there is an extensive body of work on the problems of strategic development. V.A. Gachko, E.A. Knyazeva, Z. I. Salbieva, E.I. Chaprak in his studies on economics considers the issues of strategic planning of the education system, E.P. Belan studies the pedagogical aspects of the strategic management of higher education institutions, M.G. Yanova, V.V. Ignatova - pedagogical strategies for the formation of the organizational culture of the future teacher.

Various approaches to strategizing education, the specifics of modern strategies are analyzed by such scientists as I. Ansoff, N. Barnett, G.I. Bondarenko, A.P. Valitskaya, O. I. Genisaretsky, V.I. Zagvyazinsky, E.M. Davydova, V.M. Zuev, G.L. Ilyin, O.S. Isser, M.R. Kuhn, A.S. Meshcheryakov, A. Neklessa, S. I. Plaksiy, V.N. Turchenko, Yu.S. Tyunnikov, K.S. Fursov, A.A. Shelupanov, K. Schneiderberg and others.

The theoretical provisions of strategic forecasting and design of higher education are developed by O.I. Genisaretsky, B.S. Gershunsky, V.M. Zuev, A.P. Markov, V.E. Radionov, Yu.G. Tatur. Educational strategies as values of current higher education are studied by V.S. Bibler, L.P. Buyeva, B.S. Gershunsky, V.P. Zinchenko, M.S. Kagan, A. Maslow, N.M. Ogarkov, M.A. Rozov, L.I. Romankova, R. Singh, A.V. Sokolov, L.A. Syrodeeva, V.E. Shukshunov, P.G. Shchedrovitsky and others.

Projective strategies of higher education are studied in their works by M.V. Boguslavsky, E.V. Bondarevskaya, A.P. Valitskaya, O. Yu. Glaissner, I.Z. Glikman, L.I. Gurie, I.A. Kolesnikova, N.A. Lyz, A.I. Pavlenko, N.I. Pak, I.S. Sergeev, B. Yu. Shcherbakov, etc.

The above works testify to the fact that the concept of pedagogical strategy is one of the central in modern pedagogy. It is important to emphasize that the concept of pedagogical strategies has one significant and relevant connotation - these are innovative strategies, strategies of innovative transformations, the implementation space of which is higher school. Innovative strategies of higher education in methodology are interpreted as a universal basic component of the current educational paradigm. The scientific support of «strategic» pedagogy is a strategic methodology, a strategic approach based on the forms of strategic analysis of pedagogical reality.

The innovative strategy for the development of higher education as a key factor in the modernization of education is interpreted by many domestic and foreign scientists, such as G. Becker, M.N. Berulava, A.G. Bermus, A.P. Valitskaya, I. Vleimnik, G. I. Gerasimov, V.I. Zagvyazinsky, O.A. Zamulin, A.K. Erokhin, L.V. Ilyukhina, N.V. Karlov, E. Ya. Kogan, E.M. Korotkov, J. Coleman, R. Coates, A.A. Kuzmina, E.B. Kurkin, G.F. Kutsev, 
F. Kubart, Yu.V. Myachin, J. Knight, A.I. Nelessa, R.M. Petruneva, S.I. Plaksiy, P.D. Sarkisov, G.G. Sillaste, G. Stigler, V.A. Shturba, etc.

Today, there are many definitions of the concept of pedagogical strategy, belonging to various authors. In one of the widespread theoretical interpretations, a pedagogical strategy is «skillful leadership, a consciously constructed set of pedagogical actions adequate to the pedagogical goal, carried out sequentially in stages and developed through a qualitative selection of pedagogical support: the content of the academic discipline (education), flexible use of forms, methods, funds aimed at implementing a specific strategy» [17].

Based on the theoretical principles gleaned from the collective monograph of V.V. Ignatova and M.G. Yanova [18]. Yu.V. Kosolapova defines a pedagogical strategy as «an organizational component of a teacher's pedagogical culture, namely, as a leadership, a consciously constructed set of pedagogical actions adequate to a pedagogical goal, carried out in a sequential-stepwise manner and developed through a qualitative selection of pedagogical support (content, forms, methods, techniques, means)» [19]. The researcher considers pedagogical strategy, on the one hand, as an activity with the goal of «a strategic landmark and means of achieving it (tactics). On the other hand, [as] a process taking place in time, representing the design of a set of expedient actions aimed at achieving a certain result» [19].

I.A. Kolesnikova and E.V. Titov emphasize the value-semantic dominant of professional pedagogical activity in the content structure of the strategy. The main purpose, the meaning of the pedagogical strategy in their understanding is that the strategy sets the vector of professional activity development and predicts its effectiveness [20], specifying at this is that the form of strategic plans implementation is determined by tactics.

\section{Conclusions}

In research circles, the pedagogical strategy, which characterizes the focus of the teacher's attention on the educational goal, is defined as a generalized characteristic of the teacher's activity, focused on solving professional problems and carried out in order to achieve a given strategic landmark of the pedagogical process.

Pedagogical strategy is the highest level of theoretical development of pedagogical activity. Its methodological basis is made up of such characteristic coordinates as the ability to penetrate into the essence of pedagogical reality, actualization of links between theoretical and practical meanings, formulation of goals, setting up education / training tasks, guided by the basic principles of pedagogical interaction.

The problematization of the concept of pedagogical strategy in its current understanding is associated with a complex of ideas, including a formed complex of pedagogical actions that correspond to the set pedagogical goal, which are developed sequentially and step by step, thanks to the choice of pedagogical support of the academic discipline, the use of the necessary methods, forms, means and techniques, to achieve the desired / expected state of the target.

The choice of a pedagogical strategy is determined by many factors, such as: a strategic reference point, strategic goal, strategic orientation, strategic plan, strategic prospects, and strategic objectives. Strategic development is determined by the forms, methods, strategic technologies and tools corresponding to strategic ideas. The choice of pedagogical strategy is also influenced by the level of pedagogical skill of the teacher, the availability of possible means of planned goal achieving.

Summing up our reasoning, we emphasize the following. Today, the importance of the strategic vector of higher education pedagogy is becoming more and more obvious, while the problematization of higher education is a kind of strategic resource of modern 
pedagogy. The use of pedagogical strategies is truly effective if it is ensured by harmonious integration with the systemic essence of current education.

\section{References}

1. V. L. Kvint, Manag. Consult., 1, 15 (2016)

2. V. I. Zagvyazinsky, A. F. Zakirova, Pedagogical dictionary (2008)

3. A. Reber, Big explanatory psychological dictionary, 2 (2001)

4. A. N. Petrov, Problems of Modern Economics, 1-2 (9-10) (2004)

5. B. M. Bim-Bad, Pedagogical encyclopedic dictionary (2003)

6. H. Mintzberg, California Management Review, 19 (1978)

7. K. O. Chepelenko The author in the context of the space of art: on the example of the creative strategies of contemporary Russian composers (2017)

8. K. O. Chepelenko, Hist., Phil., Polit. and Leg. Sc-s, Cult. Stud. and Art Hist. Quest. of Theor. and Pract., 9 (71), 200 (2016)

9. K. O. Chepelenko, Hist., Phil., Polit. and Leg. Sc-s, Cult. Stud. and Art Hist. Quest. of Theor. and Pract., 10 (72), 197 (2016)

10. K. O. Chepelenko, Hist., Phil., Polit. and Leg. Sc-s, Cult. Stud. and Art Hist. Quest. of Theor. and Pract., 4 (78), 216 (2017)

11. K. O. Chepelenko, World science: problems and innovations: collection of conference proceedings. VIII International scientific-practical conference, 1, 292 (2017)

12. K. O. Chepelenko, Innovative scientific research: theory, methodology, practice: collection of conference proceedings. VII International scientific-practical conference, 172 (2017)

13. K. O. Chepelenko, Innovative development of modern science: problems, patterns, prospects: collection of conference proceedings. International scientific-practical conference, 118 (2017)

14. O. A. Krivtsun, Art. Hist., 1, 462 (2002)

15. A. A. Romanov, System analysis of the regulatory means of dialogical communication (1988)

16. D. L. Konstantinovsky, Inequality and education. The experience of sociological research on the life start of Russian youth (1960s - early 2000s) (2008)

17. M. G. Yanova, Pedagogical strategies for the formation of the organizational culture of the future teacher, https://www.sworld.com.ua/

18. V. V. Ignatova, M. G. Yanova, Formation of the organizational and pedagogical culture of the future teacher (theoretical and methodological aspect) (2011)

19. Yu. V. Kosolapova, Maintenance of the teacher's professional activity on the introduction of federal state educational standards for general education (2015)

20. I. A. Kolesnikova, E. V. Titova, Pedagogical praxeology (2005) 